Original Research Article

\title{
Drug utilization study of bronchial asthma in adults at rural hospital
}

\author{
Ameya Puranik*, Sangita Totade
}

Department of Pharmacology, Jawaharlal Nehru Medical College, Sawangi (Meghe), Wardha, Maharashtra, India

Received: 18 October 2018

Revised: 14 November 2018

Accepted: 29 November 2018

*Correspondence to:

Dr. Ameya Puranik,

Email: ameypuranik1@ gmail.com

Copyright: (C) the author(s), publisher and licensee Medip Academy. This is an openaccess article distributed under the terms of the Creative Commons Attribution NonCommercial License, which permits unrestricted noncommercial use, distribution, and reproduction in any medium, provided the original work is properly cited.

\begin{abstract}
Background: Asthma is rather a clinical syndrome than a disease with availability wide range of medications. Drug utilization studies are necessary to improve prescribing pattern among physicians.

Methods: The 250 study subjects were interviewed, and prescription data was recorded in a pre-designed case record form. The data was compiled using Microsoft excel and presented in a tabulated and graphical presentation.

Results: Out of 250 study subjects most of the study subjects are between 61-70 years of age. Majority of subjects are males $(58 \%)$. Out of $250,(49 \%)$ are found out to be smokers. Dust, smoke and pollen are found out to be most common allergen. Most common type of asthma was mild intermittent (134) study subjects. Socio-economic status of was found out to be lower middle class in majority (158 out of 250). Large number of study population is suffering from co-morbid conditions such as URTI and COPD. Salbutamol was most common single drug used for nebulization therapy and most common combination is salbutamol + ipatropium bromide + budesonide. Most common oral drug used are methylxanthines and most frequently used intravenous drugs are deriphylline and hydrocortisone. Various antibiotics are prescribed to majority of subjects, most common was amoxicillin + clavulanic acid combination. Most commonly suffered adverse drug reaction between study subjects were gastrointestinal disturbances.

Conclusions: It is concluded that prescribing pattern for asthma at A.V.B.R.H. is not according to standard guidelines, hence it is need of the hour to encourage physicians to follow guidelines.
\end{abstract}

Keywords: Brochial asthma, Drug utilization, Prescription pattern, Rural hospital

\section{INTRODUCTION}

Asthma as per the GINA definition, Asthma is a heterogeneous disease, usually characterized by chronic airway inflammation. It is defined by the history of respiratory symptoms such as wheeze, shortness of breath, chest tightness and cough that vary over time and in intensity, together with variable expiratory airflow limitation. ${ }^{1}$

Bronchial asthma is a complex disease with several clinically well-defined pathogenic components, including recurrent reversible airway obstruction, chronic airway inflammation and development of airway hyperresponsiveness. ${ }^{2}$ Airway inflammation is the primary problem in asthma. An initial event in asthma is release of inflammatory mediators (e.g., histamine, tryptase, leukotrienes and prostaglandins) triggered by exposure to allergens, irritants, cold air or exercise. The mediators are released from bronchial mast cells, alveolar macrophages, $\mathrm{T}$ lymphocytes and epithelial cells. Some mediators directly cause acute bronchoconstriction, termed as earlyphase asthmatic response elements.

The inflammatory mediators also direct the activation of eosinophils and neutrophils, and their migration to the airways, where they cause injury, these so-called latephase asthmatic response results in epithelial damage, airway edema, mucus hypersecretion and hyperresponsiveness of bronchial smooth muscle. Varying 
airflow obstruction leads to recurrent episodes of wheezing, breathlessness, chest tightness and cough. ${ }^{3-5}$

Asthma is considered $14^{\text {th }}$ most important disorder epidemiologically in terms of extent and duration of disability. According to recent global asthma report, 334 million people worldwide suffer from asthma globally. ${ }^{6}$

About $8.6 \%$ of young adults worldwide between the age group of 18 to 45 suffer from asthmatic symptoms and $4.5 \%$ of young adults have been diagnosed with bronchial asthma and are taking treatment for the disease. Age groups which suffer the most are children between ages of 10 to 14 years and elderly aged between 75 to 79 years. ${ }^{7}$

The prevalence of asthma has been estimated to range 3$38 \%$ in children and $2-12 \%$ in adults varying amongst various regions. 8 A recent Indian study on epidemiology of asthma, respiratory symptoms and chronic bronchitis (INSEARCH) which included 85,105 men and 84,470 women from 12 urban and 11 rural sites in India estimated the prevalence of asthma in India to be $2.05 \%$ among those aged >15years, with an estimated national burden of 18 million asthmatics. ${ }^{9}$

Drug utilization review is the process by which the quality of drug prescribing is measured against explicitly determined criteria or standards. It is a dynamic process aimed firstly at rational prescribing and the consequent improvement of the quality of care, and secondly, at minimizing expenditures. These reviews have been an important component of efforts to improve prescribing practices in both institutional and ambulatory care settings. It provides the mechanism for developing standards, assessing current therapy, and implementing a specific intervention followed by reassessment of drug utilization. ${ }^{10}$

The current study aims to analyze drug utilization of asthma therapy in adults using quantitative type of data used for prescription auditing to reproduce the observations according to the extent of variability in their usage in health care system.

\section{Objectives}

- To observe trends of drug prescribing pattern of bronchial asthma.

- To analyze gender, age and socio-economic distribution of asthma patients.

- To observe commonly prescribed single and combination of drugs given by various routes of drug administration.

\section{METHODS}

It was a cross-sectional observational study. This study was carried out in Department of Respiratory Medicine, General Medicine and Department of Pharmacology at Acharya Vinoba Bhave Rural Hospital Sawangi (Meghe),
Wardha (M.S.). The study duration was 2 years. The study was initiated only after approval of Institutional Ethics Committee.

\section{Inclusion criteria}

- Patients diagnosed with bronchial asthma clinically or on spirometry

- Patients of age 18 years and above

- Patient giving oral and written consent to participate in the study

- Patients with co-morbid condition as COPD, URTI, LRTI and related conditions

- Patient admitted in In-patient department.

\section{Exclusion criteria}

- Patients below 18years of age

- Patients with anxiety disorders and related psychiatric conditions mimicking bronchial asthma.

- Patients diagnosed with chronic lung infections such as tuberculosis and HIV related opportunistic infections.

- Patients clinically diagnosed with lung malignancies.

- Patients with severely compromised cardiac, renal or hepatic function.

- Patients who refused to give oral and written consent.

- Patient receiving treatment from outpatient department.

Materials included in the study were patient case record form and validated consent form.

This study was a cross-sectional observational single centred, in which patients of either sex of age group 18years, who were willing to participate in the study were recruited by signing the consent form in patient friendly language, as patient interview in an important part of the study, the patient was interview once the vitals are stable and acute symptoms were subsided.

The detailed semi-structured proforma (case record form) and a validated consent form were designed as a tool for the case collection in the consultation with the guide for assessment of drug utilization after interviewing and recording prescription written by the treating doctor. The proforma was pretested on 20 patients and the necessary corrections were included. The investigator attended the in-patient department along with the consultant physician.

A total of 250 patients who met the inclusion criteria were interviewed about the complete history of history of presenting illness, past medical history, history of allergy, history of smoking (if any), socioeconomic status was calculated after interview of study subjects according to modified Kuppuswamy scale, occupational history and adverse drug reaction (if any) occurred during current therapy and the prescription given to the respective patients were recorded and separated according to the 
dosage form and class of the drug. The recorded data was tabulated systemically in Microsoft excel sheet for systematic analysis.

\section{Source of data}

Patient admitted as a diagnosed case of Bronchial Asthma in Respiratory Medicine and General Medicine Department in wards and ICU OF Acharya Vinoba Bhave Rural Hospital.

\section{Type of data}

Both qualitative as well as quantitative data were assessed for the outcome assessment.

\section{Statistical analysis}

At the end of the present study, the data collected were compiled using Microsoft Excel Worksheet and processed by using appropriate statistical software. The collected data was analyzed statistically using chi-square test. A pvalue of less than 0.05 was considered to be statistically significant. In the end, the analyzed data was presented in a tabulated and by graphical presentation.

\section{RESULTS}

According to results in Table 1, most patients in this study are found to be between ages of 40-70years with most of them are between age of 61-70years (66 patients). In this study as shown in Table 2, gender distribution of study subjects has found that males $(58 \%)$ are more prone to develop asthma than females $(42 \%)$.

\section{Table 1: Distribution of study subjects according} to age.

\begin{tabular}{|lll|}
\hline Age group & Number & Percentage \\
\hline $18-20$ & 13 & $5.20 \%$ \\
\hline $21-30$ & 36 & $14.40 \%$ \\
\hline $31-40$ & 24 & $9.60 \%$ \\
\hline $41-50$ & 37 & $14.80 \%$ \\
\hline $51-60$ & 55 & $22.00 \%$ \\
\hline $61-70$ & 66 & $26.40 \%$ \\
\hline $71-80$ & 15 & $6.00 \%$ \\
\hline $81-90$ & 2 & $0.80 \%$ \\
\hline $91-100$ & 2 & $0.80 \%$ \\
\hline Total & 250 & 100 \\
\hline
\end{tabular}

Table 2: Distribution of study subjects according to gender.

\begin{tabular}{|lll|}
\hline Gender & Number & Percentage \\
\hline Male & 144 & 57.6 \\
\hline Female & 106 & 42.4 \\
\hline Total & 250 & 100 \\
\hline
\end{tabular}

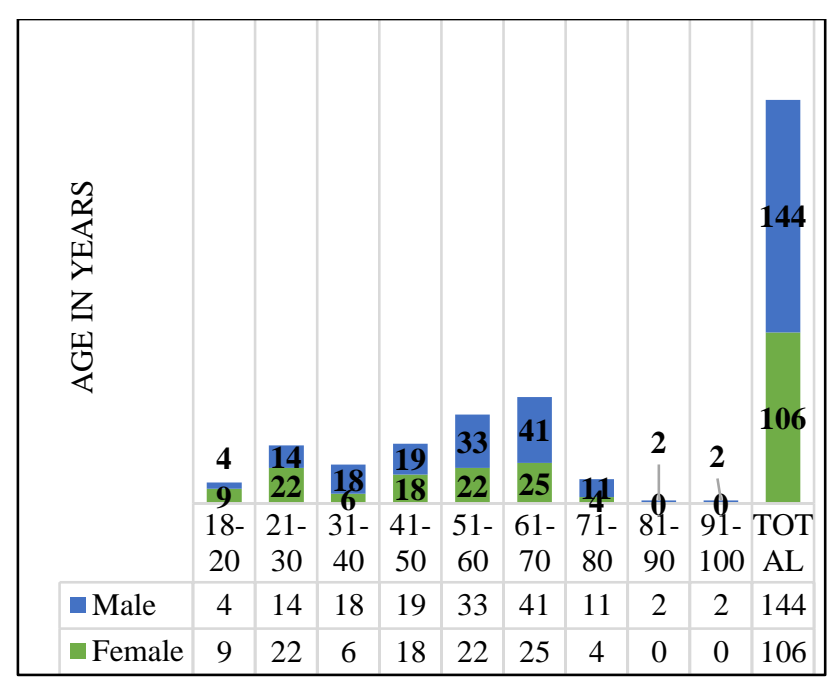

Figure 1: Age distribution according to gender.

Cross-tabulation data of comparison between age and gender-wise distribution of study subjects has shown that (Figure 1), most of the study subjects are between ages of 61-70 (66 subjects) and majority of them are males (41 subjects).

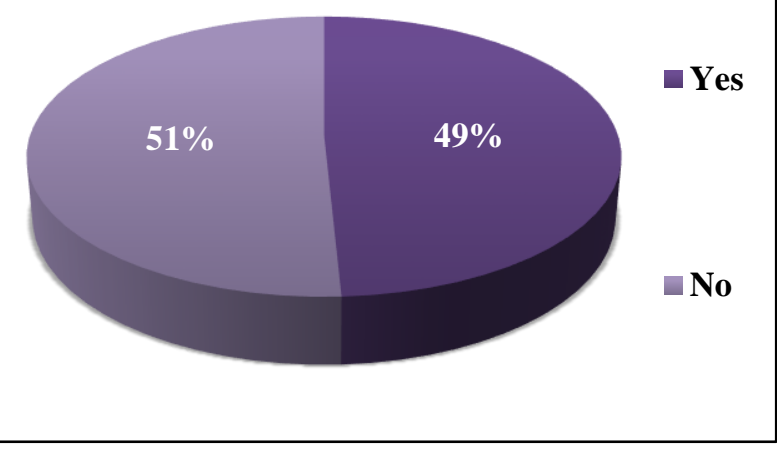

Figure 2: Distribution of study subjects according to H/O Smoking.

In this study it is found that, $51 \%$ study subjects are found to be smokers and $49 \%$ found to be smokers as per shown in Figure 2.

Table 3: Distribution of study subjects according to type of allergy.

\begin{tabular}{|lll|}
\hline Allergies & Frequency & Percent \\
\hline Coal dust & 8 & $3.2 \%$ \\
\hline Dust & 64 & $25.6 \%$ \\
\hline Dust, pollen & 4 & $1.6 \%$ \\
\hline Dust, smoke & 36 & $14.4 \%$ \\
\hline Pollen & 3 & $1.2 \%$ \\
\hline Smoke & 46 & $18.4 \%$ \\
\hline None & 89 & $35.6 \%$ \\
\hline Total & 250 & $100.00 \%$ \\
\hline
\end{tabular}


In this Study subjects with established allergies (Table 3) were found to be most commonly have allergies to dust, smoke and pollen. Dust is found to be most common individually in 64 study subjects.

Table 4: Distribution of study subjects according to type of asthma.

\begin{tabular}{|lll|}
\hline Age & Number & Percentage \\
\hline Mild intermittent & 138 & $55.2 \%$ \\
\hline Mild persistent & 64 & $25.6 \%$ \\
\hline Moderate persistent & 43 & $17.2 \%$ \\
\hline Severe persistent & 5 & $2 \%$ \\
\hline Total & 250 & 100 \\
\hline
\end{tabular}

As demonstrated in Table 4, most of the study subjects are observed to have mild type of asthma with mild intermittent type is most prevalent (138 patients) followed by mild persistent type ( 64 patients).

Table 5: Distribution of study subjects according to socioeconomic status.

\begin{tabular}{|lll|}
\hline Age & Number & Percentage \\
\hline Upper class & 3 & $1.2 \%$ \\
\hline Upper middle class & 13 & $5.2 \%$ \\
\hline Lower middle class & 158 & $63.2 \%$ \\
\hline Upper lower & 71 & $28.4 \%$ \\
\hline Lower & 5 & $2 \%$ \\
\hline Total & 250 & 100 \\
\hline
\end{tabular}

Majority of the study subjects in this study are from lower middle class (158) followed by upper lower class (71) according to Kuppuswamy scale (Table 5).

Table 6: Distribution of study subjects according to associated comorbidity.

\begin{tabular}{|lll|}
\hline Co-morbid conditions & Number & Percentage \\
\hline $\begin{array}{l}\text { COPD with/without } \\
\text { complications }\end{array}$ & 45 & $18 \%$ \\
\hline URTI and related conditions & 86 & $34.4 \%$ \\
\hline LRTI and related conditions & 16 & $6.4 \%$ \\
\hline Others & 20 & $8 \%$ \\
\hline None & 83 & $33.2 \%$ \\
\hline Total & 250 & $100 \%$ \\
\hline
\end{tabular}

Most common co-morbid conditions present in study subjects is upper respiratory tract infections and related conditions (Table 6) e.g. pharyngitis, sinusitis (86 subjects), second most common co-morbid condition was found observed to be chronic obstructive pulmonary disease (COPD) with or without complications e.g. Cor pulmonale (45 subjects).

Majority of the study subjects received nebulization as an emergency medication and for maintenance purpose in respective doses and combination according to symptoms and severity of asthma, and most common drugs are: Salbutamol alone is used in $(30 \%)$ of subjects. budesonide and duolin (ipratropium bromide + salbutamol) as an combination is most used in $36 \%$ of subjects, and only $2 \%$ of subjects did not receive any medication as symptoms were not severe, and controlled by inhalers and oral medication (Table 7).

Table 7: Distribution of study subjects according to drug used for nebulization.

\begin{tabular}{|lll|}
\hline Drug used & Number & Percentage \\
\hline Salbutamol & 74 & $29.6 \%$ \\
\hline Levosalbutamol & 8 & $3.2 \%$ \\
\hline Salbutamol + budesonide & 72 & 28.8 \\
\hline $\begin{array}{l}\text { Salbutamol + ipratropium } \\
\text { bromide + budesonide }\end{array}$ & 91 & $36.4 \%$ \\
\hline NIL & 5 & $2 \%$ \\
\hline Total & 250 & $100 \%$ \\
\hline
\end{tabular}

Table 8: Distribution of study subjects according to anti-asthmatic drug used as oral tablet.

\begin{tabular}{|lll|}
\hline Drug used & Frequency & Percentage \\
\hline Beta-2 agonist & 12 & $4.8 \%$ \\
\hline Methylxanthines & 82 & $32.8 \%$ \\
\hline Acebrophylline & 41 & $16.4 \%$ \\
\hline Montelukast & 18 & $7.2 \%$ \\
\hline Prednisolone & 12 & $4.8 \%$ \\
\hline Nil & 85 & $34 \%$ \\
\hline Total & 250 & 100 \\
\hline
\end{tabular}

Table 9: Distribution of study subjects according to Intravenous anti-asthmatic agents.

\begin{tabular}{|lll|}
\hline Drug used & Frequency & Percentage \\
\hline $\begin{array}{l}\text { Deriphylline (theophylline } \\
\text { + etofylline) }\end{array}$ & 73 & $29.2 \%$ \\
\hline Hydrocortisone & 35 & $14 \%$ \\
\hline $\begin{array}{l}\text { Deriphylline + } \\
\text { hydrocortisone }\end{array}$ & 35 & $14 \%$ \\
\hline NIL & 107 & $42.8 \%$ \\
\hline Total & 250 & $100 \%$ \\
\hline
\end{tabular}

Out of 250 study subjects, 165 received oral antiasthmatics. Most commonly 5 classes of drugs are observed to be given very frequently. These are: salbutamol, methyxanthines (deriphylline and doxofylline), acebrophylline, montelukast and prednisolone. Out of these five drugs methyxanthines (deriphylline and doxophylline) are most commonly used drugs (82 subjects) followed by mucoregulator Acebrofylline (41 subjects) (Table 8).

In this study it is observed that most patient were given intravenously anti-asthmatics for symptomatic relief in emergency. Only two drugs are seen to be given as single 
drug or in combination i.e. deriphylline (theophylline +etofylline) and hydrocortisone (Table 9).

\section{Table 10: Distribution of study subjects according to type of antibiotics.}

\begin{tabular}{|lll|}
\hline Drug used & Frequency & Percentage \\
\hline Amoxicillin & 76 & $30.4 \%$ \\
\hline $\begin{array}{l}\text { Amoxicillin + clavulanic } \\
\text { acid }\end{array}$ & 82 & $32.8 \%$ \\
\hline Azithromycin & 33 & $13.2 \%$ \\
\hline Clindamycin & 18 & $7.2 \%$ \\
\hline Roxithromycin & 6 & 2.4 \\
\hline Others & 13 & $5.2 \%$ \\
\hline None & 22 & $8.8 \%$ \\
\hline Total & 250 & 100 \\
\hline
\end{tabular}

Table 11: Distribution of study subjects according to type of adverse drug reactions.

\begin{tabular}{|lll|}
\hline ADR & Frequency & Percent \\
\hline Gastritis/hyperacidity & 70 & $28 \%$ \\
\hline Headache & 13 & $5.20 \%$ \\
\hline Nausea and vomiting & 7 & $2.40 \%$ \\
\hline Resting Tremors & 18 & $7.20 \%$ \\
\hline $\begin{array}{l}\text { Spasmodic G.I. } \\
\text { pain/diarrhoea }\end{array}$ & 47 & $0.40 \%$ \\
\hline None & 94 & $37.60 \%$ \\
\hline Total & 250 & $100.00 \%$ \\
\hline
\end{tabular}

It has been observed in this study that, 228 out of 250 i.e. about $91.2 \%$ of study subjects were given antibiotics along with other anti-asthmatic and symptomatic medications as per shown in (Table 10). Antibiotics were prescribed to treat co-morbid infections such URTI or to prevent secondary infections. Most commonly prescribed antibiotic prescribed was Amoxicillin, alone or in combination with clavulanic acid (76 out of 228). Other commonly used antibiotics are azithromycin, clindamycin and roxithromycin in descending order.

Out of 250 subjects in this study 155 subjects have experienced adverse drug reactions to given drugs. Of all 155 subjects, large number of subjects have suffered gastritis, hyperacidity, spasmodic gastrointestinal pain and diarrhoea (Table 11). It has also been observed that, these adverse drug effects were most common in patients taking antibiotics.

Cross table comparison between study subjects according to nebulization given to study subjects with type of asthma in (Table 12) has shown that, combination of 2 to 3 drugs is more preferred in study subjects with persistent type of asthma (mild, moderate, severe) and single drug therapy i.e. salbutamol/ levosalbutamol is more preferred in study subjects with mild intermittent type of asthma. The p-value on chi-square, was found out to be statistically significant.
Table 12: Comparison of study subjects according to type of asthma and nebulization prescribed.

\begin{tabular}{|llll|}
\hline \multicolumn{3}{|l|}{ Nebulization vs type of asthma } & \\
\hline Nebulization & Intermittent & Persistent & Total \\
\hline $\begin{array}{l}\text { Salbutamol } \\
\text { +ipratropium } \\
\text { bromide + } \\
\text { budesonide }\end{array}$ & 43 & 48 & 91 \\
\hline NIL & 3 & 2 & 5 \\
\hline $\begin{array}{l}\text { Salbutamol/ } \\
\text { levosalbutamol }\end{array}$ & 56 & 26 & 82 \\
\hline $\begin{array}{l}\text { Salbutamol + } \\
\text { budesonide }\end{array}$ & 37 & 35 & 72 \\
\hline Total & 138 & 112 & 250 \\
\hline
\end{tabular}

Chi square- $8.476, \mathrm{P}$-value $=0.0371(<0.05)($ significant $) \mathrm{df}=3$

\section{DISCUSSION}

The present study was undertaken to evaluate the drug utilization pattern of Bronchial Asthma in adult patients at rural hospital setting. This was considered as aim of the study.

A total of 250 patients were included in the study all are clinically diagnosed of bronchial asthma, and admitted in ward or ICU of A.V.B.R.H.

In this study, age distribution of the study subjects is mostly between 51 to 70 years of age (121 out of 250 i.e. approximately $48 \%$ ) (Table 1). Thus about half of the subjects suffering from bronchial asthma are in sixth and seventh decades of their life, with majority of them are between the age of 61 to 70 years of age ( 66 subjects) with most of them are males (Figure 1) while similar study conducted by Jagadeesan et al, at Raja muthaiah medical college and Hospital, Annamalai Nagar, Chidambaram, has shown that majority of study subjects are between the ages of 40 to 49 . This variation in age group could be because of different environmental / genetic factors in both studies. $^{11}$

The gender distribution in this study has shown that $58 \%$ study subjects are males and $42 \%$ of the study subjects are females, thus males are observed to be affected more than females, but only by the short range of difference only (Table 2). However, similar study conducted by Arumugam $\mathrm{V}$ et al, Dehradun at various hospitals in Dehradun has observed that males $(64 \%)$ were suffering more from asthma than females $(36 \%)$. Hence the range of difference in number of females than males is larger. ${ }^{12}$

On categorizing the study subjects according to severity of asthma, it is observed that majority of patients are suffering from mild intermittent type of asthma (138 out of 250 i.e. $55.2 \%$ ). Thus, more than half of subjects are suffering from mild intermittent type of asthma while only approximately $44.8 \%$ are suffering from persistent type of asthma (Table 4). While contrast has been seen in another study 
conducted by Zahran et al, has observed that, $64.8 \%$ met the definition of persistent type of asthma and $35.2 \%$ met the definition of intermittent type of asthma. This difference might be because of geographical and environmental difference between the regions where study was conducted. ${ }^{13}$

Allergy is an important factor in asthma, in this study environmental allergen dust, smoke is found to most commonly occurring allergen when history of allergy was taken from study subjects. Out of 250 subjects 64 subjects gave history of allergy to dust, 46 subjects gave history of allergy smoke individually, and 36 subjects gave history of having allergy to both dust and smoke (Table 3), while similar study conducted by Jagadeesan et al, has recorded that cold air as most common allergen in $54 \%$ of study subjects. ${ }^{11}$

Inhalational therapy is commonest form of method used for drug delivery as most study subjects are symptomatic, majority of patients $(98 \%)$ have received nebulization, most common individual drug given as nebulization is Salbutamol (30\%) and most commonly given drug combination used is Salbutamol + ipratropium bromide + budesonide, which is given to $36 \%$ of study subjects (Table 7). Similar study conducted by Jyothi DB et al, at a tertiary care centre, Bidar also showed that individually Salbutamol is most common drug given in inhalational form, given to $90 \%$ of study subjects. ${ }^{14}$

In this study oral anti-asthmatic drugs were also prescribed to many study subjects as an adjuvant to nebulization therapy. Most common drugs given in oral therapy are methylxanthines (82 out of 165 subjects), out of methylxanthines, theophylline + etofylline in the dose range of 150 to $300 \mathrm{mg}$ is given to most of subjects, and very few patients received doxofylline (Table 8). This finding was in contrast with the similar type of study conducted by Pandey et al, at Gorakhpur, which shows that Beta-2 agonist Salbutamol was most commonly prescribed drug among practitioners in Gorakhpur. ${ }^{15}$

The present study has analyzed the drug prescribing pattern of IPD patient admitted in ward and ICU, hence symptomatic patients were also prescribed intravenous anti-asthmatic drugs to quickly relieve symptoms of asthma. Only two drugs were used for intravenous therapy i.e. theophylline + etofylline (deriphylline) and Hydrocortisone, out of 250 subjects 143 have received intravenous drugs, which are given as a single drug or in combination (Table 9). However a systemic review and meta-analysis done by Mahemuti et al, has concluded that intravenous theophylline is superior to other drugs in terms of hospital stay and overall considered to be cost-effective and safe treatment option for acute exacerbation of asthma, especially in developing countries. ${ }^{16}$ However completely contradictory to the findings of the both studies, the article cited in GINA report 2017 of a study conducted by Nair P et al, has concluded that, intravenous methyxanthines did not result in significant additional bronchodilation when compared to standard care with inhaled beta- 2 agonists in patients experiencing an acute asthma exacerbation in the emergency setting, or in a significant reduction in the risk of hospital admission. ${ }^{17}$

In this study large number of study subjects admitted with asthma, were also diagnosed with related co-morbid conditions. Out of 250 subjects 81 subjects were diagnosed with upper respiratory tract infections (URTI) and related conditions such as rhinitis, sinusitis and pharyngitis and 45 study subjects were known case of chronic obstructive pulmonary disease (COPD) (Table 6). However, two similar studies about co-relation between respiratory infections and asthma exacerbation, conducted by Atmar et al, had found the similar results that, $44 \%$ and $55 \%$ asthma exacerbations were found to be associated to respiratory tract infection. ${ }^{18}$

Out of 250 subjects, 41 were diagnosed with co-existing COPD (Table 6), this overlapping diagnosis of COPD and Bronchial asthma was also discussed by recent study in 2015, conducted by Barrecheguren et al, has concluded that Asthma COPD overlapping syndrome (ACOS) share characteristics of both asthma and COPD. ${ }^{19}$

In the present study, socio-economic history recorded after interviewing study subjects about their socio-economic status and living conditions has concluded that most of the subjects (158 out of 250 i.e. $63.2 \%$ ) belong to lower middle class living in urban and suburban areas (Table 5), Similar findings were observed in the systematic review and metaanalysis done by Jie et al, has concluded after studying several studies that, asthma and asthma-related symptoms occurred more frequently in urban areas than in rural areas. $^{20}$

Out of 250 study subjects 228 received antibiotics for comorbid infection and to prevent secondary infections and the most commonly used antibiotic is amoxicillin + clavulanic acid combination (Table 10). The role of antibiotics in asthma in doubtful, recent recommendations for management of asthma of published by joint venture of ICS/NCCP have suggested that, the use of antibiotics did not produce any significant difference in lung function and hospital stay of asthma patients, unless patients has comorbid bacterial infection. ${ }^{21}$

History of smoking habits in was recorded in this study, which shows that $51 \%$ of the study subjects are smokers and $49 \%$ are non-smokers (Figure 2) hence it is observed that half of that population of study subjects in the current study are smokers. This finding was also supported by another study conducted by Piipari et al, which found strong relationship between smoking and asthma. ${ }^{22}$

This study has observed a co-relation that, when the drugs given for nebulization, when compared with two groups of type of asthma i.e. mild intermittent and persistent group (mild, moderate, severe) has shown that combination of 2 to 3 drugs is more preferred therapy with persistent type of 
asthma (mild, moderate, severe) and single drug therapy i.e. salbutamol/ levosalbutamol is more preferred in study subjects with mild intermittent type of asthma (Table 12). The above described cross- tabulation was also found to be significant when analysis done by chi square test, this clearly shows co-relation that severity of asthma and nebulization used to control symptoms of asthma, more severe is asthma more drug combination therapy is required.

In the present study, out of 250 subjects in this study 155 subjects have experienced adverse drug reactions/ sideeffects to given prescription of drugs. Most frequently the study subjects have suffered gastritis, hyperacidity, spasmodic gastrointestinal pain and diarrhea, which were managed by symptomatic medication (Table 11). On the contrary, another study conducted specifically about pharamacovigilance in cases of bronchial asthma by Maiti $S$ et al, observed that most commonly used adverse reactions in asthma patients are, oral thrush and palpitations. This difference in observations might because, the study was conducted on patients visiting outpatient department and common medications use in the study setup are different. ${ }^{23}$

\section{CONCLUSION}

Overall, the current demonstrated that, most of the study subjects suffering from bronchial asthma are males and in the sixth decade to their lives. This shows middle age male are more prone to asthma than females, but not by the large margin of difference, the majority of study subjects suffering from asthma are from lower middle class, living in urban and suburban areas of the region. The smoke and dust are most important environmental allergens in the area causing asthma where the study was conducted, raises great concern about severity of pollution in the region. Approximately $98 \%$ patients were given nebulization, this shows most practitioners at A.V.B.R.H are aware of and follow recent asthma management guidelines for acute exacerbation. Methylxanthines (theophylline + etophylline) was more preferred drug used as oral tablet in this study. In the current study, only $36.8 \%$ patient were diagnosed with URTI/LRTI, but $91.2 \%$ patients were prescribed various antibiotics, this raises concerns about overuse of antibiotics by prescribing doctors in this study setup.

\section{ACKNOWLEDGEMENTS}

Authors would like to thank Department of Pharmacology, and Department of Respiratory Medicine, Jawaharlal Nehru Medical College, Sawangi (Meghe), Wardha, Maharashtra, India.

Funding: No funding sources Conflict of interest: None declared

Ethical approval: The study was approved by the Institutional Ethics Committee

\section{REFERENCES}

1. Global Initiative for Asthma. Global strategy for the diagnosis and prevention. Global Initiative for Asthma. 2017. Available at: https://ginasthma.org/wpcontent/uploads/2017/02/wmsGINA-2017-mainreport-final_V2.pdfAccessed October 2018.

2. Kay AB. Pathology of mild, severe, and fatal asthma. Am J Respiratory Critical Care Med. 1996 Aug 1;154(2):S66.

3. Bethesda (MD). Expert Panel Report 3: Guidelines for the Diagnosis and Management of Asthma. National Heart, Lung, and Blood Institute (US); 2007. Available at: https://www.ncbi.nlm.nih.gov/books/NBK7232/.

4. Horwitz RJ, Busse WW. Inflammation and asthma. Clin Chest Med. 1995 Dec;16(4):583-602.

5. Djukanović R, Wilson JW, Britten KM, Wilson SJ, Walls AF, Roche WR, et al. Effect of an inhaled corticosteroid on airway inflammation and symptoms in asthma. Am Rev Respir Dis. 1992 Mar;145(3):66974.

6. Lai CKW, Beasley R, Crane J, Foliaki S, Shah J, Weiland S, et al. Global variation in the prevalence and severity of asthma symptoms: phase three of the International Study of Asthma and Allergies in Childhood (ISAAC). Thorax. 2009 Jun;64(6):476-83.

7. To T, Stanojevic S, Moores G, Gershon AS, Bateman ED, Cruz AA, et al. Global asthma prevalence in adults: findings from the cross-sectional world health survey. BMC Public Health. 2012 Dec;12(1):204.

8. Cavkaytar O, Sekerel BE. Baseline management of asthma control. Allergol Immunopathol (Madr). 2014 Apr;42(2):162-8.

9. Jindal SK, Aggarwal AN, Gupta D, Agarwal R, Kumar R, Kaur T, et al. Indian study on epidemiology of asthma, respiratory symptoms and chronic bronchitis in adults (INSEARCH). Int J Tuberc Lung Dis Off J Int Union Tuberc Lung Dis. 2012 Sep;16(9):1270-7.

10. A view from the drug utilization review management organization sector - Jones - 1991 - Clinical Pharmacology \&amp; Therapeutics - Wiley Online Library. Available at: https://ascpt.onlinelibrary.wiley.com/doi/pdf/10.1038 /clpt.1991.195. Accesses 31 July 2018.

11. Jagadeesan M. A study on concurrent drug utilization evaluation of antiasthmatic drugs in the tertiary care hospital. Int J Nov Trends Pharm Sci. 2016 Feb;6(1):14-9.

12. Arumugam V, Kothiyal P, Juyal V, Pandey A, Tripathi P. Drug utilization assessment in asthma therapy through prescription monitoring at Dehradun hospitals. Indian J Allergy Asthma Immunol. 2008;22(1):15-8.

13. Zahran HS, Bailey CM, Qin X, Moorman JE. Assessing asthma severity among children and adults with current asthma. J Asthma Off J Assoc Care Asthma. 2014 Aug;51(6):610-7. 
14. B JD, Kulkarni GP. A retrospective study on drug utilization in patients with acute exacerbation of bronchial asthma in adults at tertiary teaching hospital in Bidar. Int J Basic Clin Pharmacol. 2017 Jan 28;6(2):389-92.

15. Pandey A, Tripathi P, Pandey RD. Prescription pattern in asthma therapy at Gorakhpur hospitals. Lung India. 2010 Jan 1;27(1):8.

16. Mahemuti G, Zhang H, Li J, Tieliwaerdi N, Ren L. Efficacy and side effects of intravenous theophylline in acute asthma: a systematic review and metaanalysis. Drug Design Develop Therapy. 2018;12:99120.

17. Nair P, Milan SJ, Rowe BH. Addition of intravenous aminophylline to inhaled beta (2)-agonists in adults with acute asthma. Cochrane Database Syst Rev. 2012 Dec 12;12:CD002742.

18. Atmar RL, Guy E, Guntupalli KK, Zimmerman JL, Bandi VD, Baxter BD, et al. Respiratory Tract Viral Infections in Inner-City Asthmatic Adults. Arch Intern Med. 1998 Dec 7;158(22):2453-9.

19. Barrecheguren M, Esquinas C, Miravitlles M. The asthma-COPD overlap syndrome: a new entity? COPD Res Pract. 2015 Oct 22;1(1):8.
20. Jie Y, Isa ZM, Jie X, Ju ZL, Ismail NH. Urban vs. rural factors that affect adult asthma. Rev Environ Contam Toxicol. 2013;226:33-63.

21. Agarwal R, Dhooria S, Aggarwal AN, Maturu VN, Sehgal IS, Muthu V, et al. Guidelines for diagnosis and management of bronchial asthma: Joint ICS/NCCP (I) recommendations. Lung India. 2015 Apr 1;32(7):3.

22. Piipari R, Jaakkola JJK, Jaakkola N, Jaakkola MS. Smoking and asthma in adults. Eur Respir J. 2004 Nov 1;24(5):734-9.

23. Maiti S, Samajdar SS, Panda P, Prasad A, Pattanayak C, Das KL. Pharmacovigilance study in cases of bronchial asthma in tertiary care hospitals of eastern India. Indian J Pharm Pharmacol. 2016 Jul 28;2(2):859.

Cite this article as: Puranik A, Totade S. Drug utilization study of bronchial asthma in adults at rural hospital. Int J Basic Clin Pharmacol 2019;8:120-7. 